be administered, are well understond by the faculty. A case of mimosis recently presented itself to ine, in which obstinate constipation was one of the prominent symptoms, and yet it was not a case in which the croton oil was admissible. Medicine of any considerable bulk was also inappropriate, since the irritability of the stomach was so great as to reject it instanter, and the patient had already reached the tiremtieth day since the last evacuation from the bowels. Uuder these circumstances I was induced to try the effect of the nil externally applied, although I had never known or heard of a case in which constipation had been overcome in this manner. One drachm of the oil was accordingly rubbed over the abdomen, but it produced no apparent eflect on the botvels. Its only operation was on the skin, bringing out a very copious eruption of minute pustules, which dried away in a very few days, without producing any considerable inconvenience. These pustules were smaller than those usually excited by the antimonial nintment, and attended with less acute local inflammation or soreness. Far'ts of this kind should be recorded, since they may one day be turned to accoum in disenses requiring external irritation.

Boston, December, 1832.

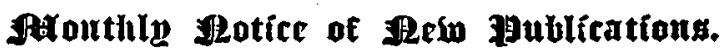

\section{Human Physiology; Illustrated by numerous Engravings. By RoBLey} Dunalison, M.D., Professor of Physiology, \&c. in the University of Virginia. 2 Vols. 8vo. Carey \& Lea, Philadelphia. 1832.

Dr. Dunglison is well known to the medical public as the author of a copious dictionary of meäical terms-a work displaying great erudition, and one which, we doubt not, will take the place of all similar publications in the hands of the profession in this country. The present work, which is somewhat more attrnctive in its subject, affords a new proof of the author's uncommon zeal and diligence in that branch of study to which he has devoted himself. The work is a complete treatise on the various functions which subserve the life of the individual and the propagation of the species, accompanied with all the descriptive details which are necessary to the elucidation of the sulject, and farther illustrated by numerous wood cuts, placed side by side with the letter press which refers to them, and giving a concise but fuithful representation of the various organs of the human body. In considering the various subjects embraced under the comprehensive title of Human Physiology, as understood in modern language, Dr. S. scems to have omitted nothing of importance that was to be found in the works of his predecessors, and has shown himself to be well acquainted with the labors of all the most distinguished physiologists of the age, both in England and on the continent of Europe. He has moreover enriched his work with much valuable information, 
which has resulted from the investigations of our own philosophers, many of which had been undeservedly neglected, and allowed to remain unnoticed in those publications in which they first made their appearance. To these the author has added many valuable facts, derived from his personal observation; so that the work may be regarded as, on the whole, the most complete treatise on Physiology we possess in our language.

When we compare the treatises on Physiology published within the last thirty years, with the standard works of the last century-the works for instance of Boerhaave and Haller-it would appear that this science, like Chemistry, had commenced almost a new existence within that comparatively brief period. Its modern history commences, it is true, rather farther back than the perind referred to. Perhaps John Hunter deserves, more than any one, the credit of having given a new inpulse to this science in the true direction. Since his time, though with very variable progress, Physiology has gradually been assuming its just rank as a science. The labors of Bichat in this field have reared an imperishable monument to his fame; and his successors, emulating his zeal, have explored in every direction this vast and mysterious region of inquiry. The contrast between the text books of the science which are now in use, and those which were put into the student's hands twenty years ago, is truly astonishing. We are not obliged to look far back to remenber the hopeless dullness in which we pored over the pages of Haller, translating his endless sentences and more endless paragraphs into the vernacular, with no one circumstance to relieve the toil of study, at a time when Bichat and Richerand were viewed almost in the light of dangerous innovators, and as having intruded on ground already in possession of its rightful owners. At present, thanks to the exertions of modern days, Physiology has become a delightful and attractive science, blending amusement with instruction, and inciting the man of taste by all the charms of eloquence, while it allures the philosopher by its appeals to his reason and his love of truth. To collect and digest into a system the known facts on so extensive a subject, has now become a serious labor; but it is one which, well executed, does honor to its author, and entitles him to the respect and gratitude of his cotemporaries.

An Bssay.on the Ganglionary System of Nerves in the Cavity of the Cranium, and its Use. By William INGalis, M.D. Boston. 1832. pp. 16.

Ir, is to be regretted that so many of those who arrive at distinction and wealth by the practice of medicine, become in advanced life indifferent to the progress of that science, to the successful cultivation of which they owe their advancement. They are too apt either to become absorbed in routine of practice, which leaves them no time for literary exertion, or rativing, on the wealth they have acquired, to become interested in 